\title{
Fruit and vegetable intake in the Czech child population
}

\author{
Marie Jakubikova, Marcela Dofkova and Jiri Ruprich* \\ Department of Food Safety and Nutrition, NIPH - National Institute of Public Health in Prague, Palackého 3a, \\ Brno 61242, Czech Republic
}

Submitted 25 January 2010: Accepted 23 November 2010: First published online 22 February 2011

\begin{abstract}
Objective: To describe fruit and vegetable intake of pre-school and school children in the Czech Republic and to provide information about their preferences and dietary habits.

Design: Cross-sectional dietary survey conducted by the method of repeated $24 \mathrm{~h}$ recall on two non-consecutive days. Usual intakes were calculated for three age categories (4-6, 7-10 and 11-14 years).

Setting: The whole area of the Czech Republic.

Subjects: A subgroup of 602 children aged 4-14 years was extracted from the representative sample of respondents participating in a national dietary survey (SISP) realized in the years 2003 and 2004.

Results: Estimated average usual intakes of fruit and vegetables were 209 (SD 69) g/d in children aged 4-6 years, 230 (SD 84) g/d in children aged 7-10 years, and 284 (SD $133) \mathrm{g} / \mathrm{d}$ and 261 (SD 140) g/d respectively in boys and girls aged 11-14 years. Only $22 \%$ of children had total daily intake of fruit and vegetables of five or more servings on the day of the survey. Fruits were consumed almost two times more often than vegetables in all age groups studied. The majority of fruit consumption comprised apples and bananas, which made up more than $60 \%$ of the whole fruit intake. Fruiting vegetables were the most frequently consumed group of vegetables. Conclusions: Fruit and vegetable intakes in all age categories were under recommended levels and the diversity of fruit and vegetables consumed by the Czech children was relatively low.
\end{abstract}

Fruit and vegetables are essential components of a healthy diet and are a significant source of vitamins, minerals and other bioactive substances. Epidemiological studies demonstrate that sufficient consumption of fruit and vegetables is a relevant protective factor against infectious and diet-related non-communicable diseases. Associations have been indicated between higher fruit and vegetable intake and reduced risk of $\mathrm{CHD}^{(1-3)}$ and stroke $^{(4)}$. A probable protective effect is also considered in connection with certain cancers ${ }^{(5,6)}$, mainly of the digestive $\operatorname{tract}^{(6,7)}$. The low energy density and high fibre content of fruit and vegetables may play a role in weight management ${ }^{(8-10)}$, which is important in view of the increasing occurrence of overweight and obesity in the European region. The prevalence of obesity continues to rise and the situation is alarming particularly among children and adolescents. These facts reflect the importance of adequate fruit and vegetable intake for human health over a whole lifetime.

Many activities to promote fruit and vegetable consumption are aimed at children because eating habits are formed in childhood and maintained to adulthood. There is scientific evidence that people who ate lots of fruit and vegetables as children have better eating habits as adults $^{(11)}$. Thus improving the availability of fruit and vegetables to children is considered an important determinant of consumption patterns. Schools offer many potential benefits as intervention sites, providing the opportunity to modify dietary behaviour and promote healthful eating patterns ${ }^{(12)}$. The Pro Children Project could be mentioned as an example of an activity designed for developing and testing effective strategies for promoting an adequate consumption level of fruit and vegetables among schoolchildren ${ }^{(13)}$. Another highprofile project at the European level, the so-called School Fruit Scheme, has been started as a union-wide intervention programme for distributing fruit and vegetables to schoolchildren ${ }^{(14)}$. There are also many other national and local projects for promoting fruit consumption in schools, such as the Dutch and Norwegian programmes ${ }^{(15,16)}$. Studies indicate that school programmes have the potential to increase fruit intake and can have a long-term impact on consumption ${ }^{(17-19)}$.

WHO/FAO recommends a minimum intake of $400 \mathrm{~g}$ of fruit and vegetables daily (excluding potatoes and tubers) for the prevention of chronic diseases ${ }^{(7)}$. In the Czech Republic the Nutrition Society recommends a daily intake of fruit and vegetables (excluding potatoes) of at least 
$500 \mathrm{~g}$, including heat-treated vegetables. The amount of vegetables consumed should be two times higher than the amount of fruit consumed ${ }^{(20)}$. Nutritional recommendations have also been issued by the Czech Ministry of Health ${ }^{(21)}$. A minimum daily intake of $400 \mathrm{~g}$ of various fruit and vegetable types is recommended in their publication and food-based dietary guidance depicted as a food pyramid is part of the recommendation. Daily consumption of three to five servings of vegetables (potatoes included) and two to four servings of fruit are the recommended quotas for the general population.

The objective of the present paper is to describe fruit and vegetable intake in pre-school and elementaryschool children (aged 4-14 years) in the Czech Republic and to provide information about their preferences and dietary habits concerning these food groups.

\section{Methods}

The results presented here are based on data collected during the individual food consumption study (Studie individuální spotřeby potravin, SISP) which was realized in the Czech Republic in 2003 and $2004^{(22)}$. SISP was a national cross-sectional dietary survey conducted by the use of repeated $24 \mathrm{~h}$ recall on an age- and genderrepresentative sample of the population. Sampling and interviews with respondents were carried out in cooperation with the market research agency, GfK Company. The assistance of a survey agency was evaluated as the best solution considering the extent of the study. The sample - 2590 males and females aged 4 to 90 years - was selected by multistage sampling combining random and quota selection based on data from the National Population and Housing Census in 2001, which served as the sampling frame. Systematic random cluster selection of urban and rural areas was followed by simple random selection of streets, buildings and households. A quota selection of sampling units (respondents) according to age and gender was the final stage. Institutionalized, homeless people and people speaking other than Czech/Slovak languages were not included. The overall response rate was $54 \% ; 31 \%$ of contacted individuals (eligible according to the quota criteria) refused to participate and 15\% did not complete the study (dropped out).
Data collection was proportionally distributed during the whole year to limit the influence of seasonality in the consumption of some foods. The calendar of the survey was organized in order to represent an adequate ratio of week and weekend days at the group level. Two nonconsecutive $24 \mathrm{~h}$ recalls were realized with every participant. Respondents were asked to report all foods and beverages consumed over a $24 \mathrm{~h}$ period (from midnight to midnight). To estimate portion sizes a picture book and household measures such as cups, graduated jars and spoons were used. Recalls were conducted as face-to-face interviews by trained interviewers and took place in the participants' households. Children up to 15 years of age were interviewed in the presence of parents. Small children were interviewed with assistance from parents. The second interview was conducted within a period of 1 to 6 months after the first recall and addressed another day of the week. Respondents received no incentives for participation. Self-reported body weight and height were used to estimate BMI.

A group of 602 children was extracted from the whole survey sample to investigate fruit and vegetable consumption. The subgroup was divided into three age categories: 4-6 years, 7-10 years and 11-14 years for the subsequent analyses (see Table 1). Growth charts yielded from the results of the sixth nationwide anthropological survey were applied to classify normal weight and overweight respondents ${ }^{(23)}$. Children within the 10th to 90th percentile range were classified as having normal weight and those exceeding this interval as overweight ${ }^{(24)}$.

Average intakes in $\mathrm{g} / \mathrm{d}$ represented by mean and standard deviation were calculated for every age category. The Multiple Source Method (MSM) program version $1 \cdot 0$ (Department of Epidemiology, German Institute of Human Nutrition Potsdam-Rehbrücke; https://nugo.dife.de/msm/) was used to estimate usual dietary intake. The amount of fruit and vegetables consumed was also expressed as the number of servings. One portion was considered equal to $80 \mathrm{~g}$ of fruit or vegetables, which is the quantity accepted as a standard portion in other studies ${ }^{(16,25,26)}$. Obtained results were compared with available recommendations ${ }^{(7,21)}$. With respect to classification of studied food groups, potatoes were not included in the vegetable group and were evaluated separately; and juices were excluded from the fruit group. The reason for this step was to have

Table 1 Characteristics of the sample of Czech children aged 4-14 years

\begin{tabular}{|c|c|c|c|c|c|c|c|c|c|c|}
\hline \multirow[b]{2}{*}{ Age category } & \multirow[b]{2}{*}{ Total $(n)$} & \multicolumn{2}{|c|}{ Body weight $(\mathrm{kg})$} & \multicolumn{2}{|c|}{ Body height $(\mathrm{cm})$} & \multicolumn{2}{|c|}{ 90th percentile } & \multicolumn{2}{|c|}{ Energy intake $(\mathrm{kJ} / \mathrm{d})$} & \multirow[b]{2}{*}{ Fat intake (\% TEI) } \\
\hline & & Mean & SD & Mean & SD & $\%$ & $n$ & Mean & SD & \\
\hline $4-6$ years & 182 & $21 \cdot 4$ & $4 \cdot 6$ & 115 & 11 & 24 & 44 & 7816 & 1438 & 36 \\
\hline $\begin{array}{l}7-10 \text { years } \\
11-14 \text { years }\end{array}$ & 311 & $32 \cdot 3$ & $7 \cdot 5$ & 137 & 11 & 17 & 54 & 8878 & 1738 & 37 \\
\hline Boys & 54 & $46 \cdot 9$ & $12 \cdot 3$ & 157 & 12 & 15 & 8 & 11537 & 3101 & 38 \\
\hline Girls & 55 & $45 \cdot 3$ & $11 \cdot 2$ & 154 & 13 & 15 & 8 & 9623 & 2315 & 38 \\
\hline
\end{tabular}

TEl, total energy intake. 
comparable categorization to other publications ${ }^{(7,27)}$. Presented results refer to edible portions of raw foods.

Data were elaborated in Paradox for Windows database version 10 (Corel Corporation, Ottawa, Canada) and statistical analyses were performed using Total Access Statistics software (FMS Inc., Vienna, VA, USA). The Kolmogorov-Smirnov goodness-of-fit test was used to determine probability distributions and the $t$ test and Mann-Whitney $U$ test were used for evaluating differences in food consumption with respect to gender or body weight. Analyses were carried out separately for all age categories. Evaluation of body weight was not performed for children aged 11-14 years because of the low number of overweight individuals in the sample.

\section{Results}

The characteristics of the children are summarized in Table 1. In the total sample, $19 \%$ of children were classified as overweight or obese. The highest proportion of overweight individuals was detected in children aged $4-6$ years (24\%).

Average usual fruit and vegetable intakes for children are summarized in Table 2. Usual intake distributions are presented in Table 3 and Fig. 1. Results showed that fruits were consumed almost twice as much as vegetables in all studied subgroups of children. No statistically significant differences between boys and girls, or between normal weight and overweight subjects, in relation to fruit and vegetable consumption emerged in any of the age categories studied.

Amounts presented in grams were recalculated as the number of servings, revealing that the usual intake of fruit and vegetables corresponded to $2 \cdot 6$ servings for children aged 4-6 years, $2 \cdot 9$ servings for children aged $7-10$ years, and 3.6 and 3.3 servings respectively for boys and girls aged 11-14 years. Only $22 \%$ of children had total daily intake of fruit and vegetables equal to five or more servings on the day of the survey.

\section{Fruit}

Average usual intakes of fruits were 139 (SD 40) g, 148 (SD 65) g, 161 (SD 86) g and 162 (SD 98) g daily for children aged 4-6 years, 7-10 years, and boys and girls aged 11-14 years, respectively. Because fruit juices are included in the fruit group in some recommendations, information about juice consumption can also be found in Table 2 . Intake of fruit juices was relatively high among the Czech children but was not taken into account in our calculations due to uncertainties about the composition of beverages classified as fruit juices. It is very probable that respondents did not distinguish between pure fruit juices, nectars and other soft drinks with fruit content. No statistically significant difference in fruit consumption between normal weight and overweight children or between boys and girls was detected.

Data regarding the most frequently consumed kinds of fruit during the year are shown in Fig. 2. Negligible differences were detected in the spectrum of consumed fruits among age categories. Apples and bananas represented more than half of all fruit intake - on average apples comprised $37 \%$ and bananas $27 \%$ of the total amount consumed. Other frequently consumed types of fruit were oranges, mandarins, peaches and grapes.

Seasonal and daily variations in fruit consumption were also studied. The highest fruit intake was registered in December (12\% of the overall annual consumption) and a higher level of consumption was also seen in January,

Table 2 Usual intakes of fruit, vegetables, juices and potatoes (g/d) among Czech children

\begin{tabular}{|c|c|c|c|c|c|c|c|c|}
\hline & & & \multirow{2}{*}{\multicolumn{2}{|c|}{$7-10$ years }} & \multicolumn{4}{|c|}{$11-14$ years } \\
\hline & \multicolumn{2}{|c|}{$4-6$ years } & & & \multicolumn{2}{|c|}{ Boys } & \multicolumn{2}{|c|}{ Girls } \\
\hline & Mean & SD & Mean & SD & Mean & SD & Mean & SD \\
\hline Fruit & 139 & 40 & 148 & 65 & 161 & 86 & 162 & 98 \\
\hline Vegetables & 69 & 33 & 79 & 35 & 123 & 8 & 101 & 45 \\
\hline Fruit and vegetables & 209 & 69 & 230 & 84 & 284 & 133 & 261 & 140 \\
\hline Juice & 100 & 139 & 86 & 114 & 23 & 62 & 71 & 81 \\
\hline Potatoes & 52 & 17 & 68 & 28 & 97 & 19 & 77 & 41 \\
\hline
\end{tabular}

Table 3 Distribution of usual intake (MSM method) of fruit and vegetables ( $g / d)$ among Czech children

\begin{tabular}{|c|c|c|c|c|c|c|c|c|c|c|c|c|}
\hline \multirow[b]{2}{*}{ Age category } & \multicolumn{6}{|c|}{ Fruit } & \multicolumn{6}{|c|}{ Vegetables } \\
\hline & P5 & P25 & P50 & P75 & P90 & P95 & P5 & P25 & P50 & P75 & P90 & P95 \\
\hline $4-6$ years & 83 & 111 & 134 & 169 & 187 & 204 & 24 & 46 & 63 & 86 & 112 & 138 \\
\hline $\begin{array}{l}7-10 \text { years } \\
11-14 \text { years }\end{array}$ & 71 & 101 & 141 & 190 & 231 & 257 & 33 & 54 & 70 & 98 & 128 & 151 \\
\hline Boys & 74 & 125 & 184 & 224 & 287 & 312 & 112 & 117 & 121 & 126 & 132 & 136 \\
\hline Girls & 52 & 118 & 162 & 218 & 218 & 346 & 52 & 74 & 85 & 114 & 156 & 202 \\
\hline
\end{tabular}

$\mathrm{P}$, percentile. 

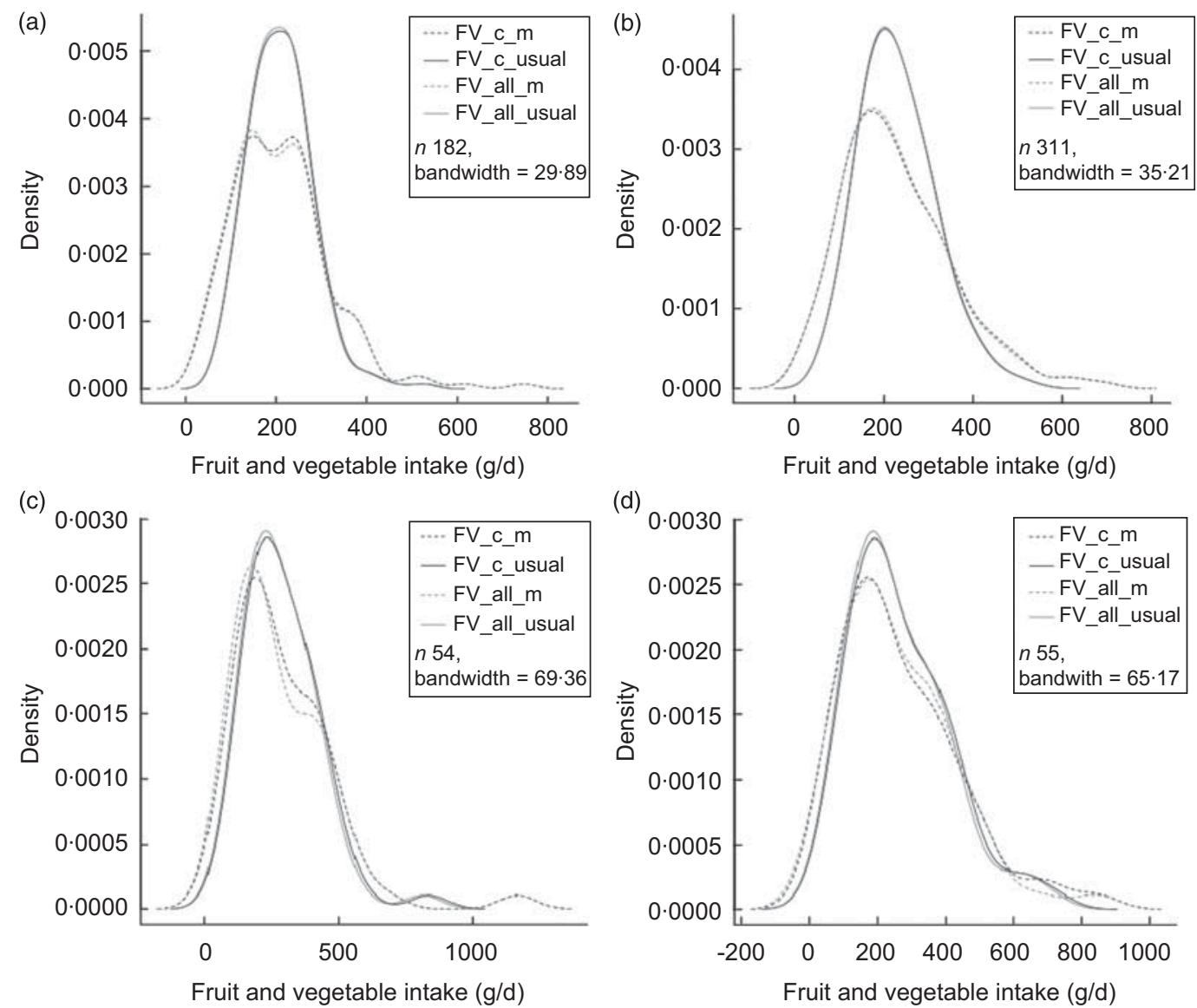

Fig. 1 Distribution (density plot) of fruit and vegetable intake in Czech children aged 4-6 years (a), 7-10 years (b), and boys (c) and girls (d) aged 11-14 years (FV_c_m, mean of the fruit and vegetable intakes on consumption days in the short-term measurement; FV_c_usual, usual daily intake of fruit and vegetables in consumers calculated by the MSM method; FV_all_m, mean of the fruit and vegetable intakes for all days of the short-term measurement; FV_all_usual, usual daily intake of fruit and vegetables for all participants calculated by the MSM method)

February and during the summer. Fruits from temperate zones were consumed mainly in the summer and tropical and subtropical fruits predominated in the winter. The lowest fruit intake was evident during May and October at only $6 \%$ of the overall annual consumption. Concerning daily variations, fruit was most often consumed as a snack during morning time and in the afternoon, less in the evening or as a part of lunch (see Fig. 3).

\section{Vegetables}

Usual average vegetable intakes (excluding potatoes) amounted to 69 (SD 33) g/d and 79 (SD 35) g/d in children aged 4-6 and 7-10 years, and 123 (sD 8) g/d and 101 (sD 45) $\mathrm{g} / \mathrm{d}$ for boys and girls aged 11-14 years, respectively. Potatoes are included in the vegetable food group in some national recommendations ${ }^{(21)}$, which is why potato intake values are also shown in Table 2 . No statistically significant difference related to vegetable intake was detected between normal weight and overweight individuals or between boys and girls.

The proportion of different vegetable groups consumed during the year is presented in Fig. 4. Fruiting vegetables (mainly tomatoes, cucumbers, green peppers and water melons) made up $35 \%$ of all vegetables consumed. This vegetable subgroup was the most frequently consumed in all surveyed age categories. Other most frequently consumed subgroups - root vegetables (carrots, celeriac, parsley) and bulbous vegetables (onions, garlic, leek) - amounted to $17 \%$ and $14 \%$ of the overall consumption, respectively.

As for seasonal variation, vegetable consumption was highest in the summer period whereas in winter time it was markedly lower. The amount of vegetables consumed during summer months (June-September) made up more than $45 \%$ of the overall annual consumption. Data regarding daily variations in vegetable consumption are shown in Fig. 5. Almost all vegetables were consumed during lunch. Hot meals are most frequently consumed at lunchtime in the Czech Republic.

\section{Discussion}

Description of usual intake distribution in a population is of cardinal importance for assessment of nutritional status. 


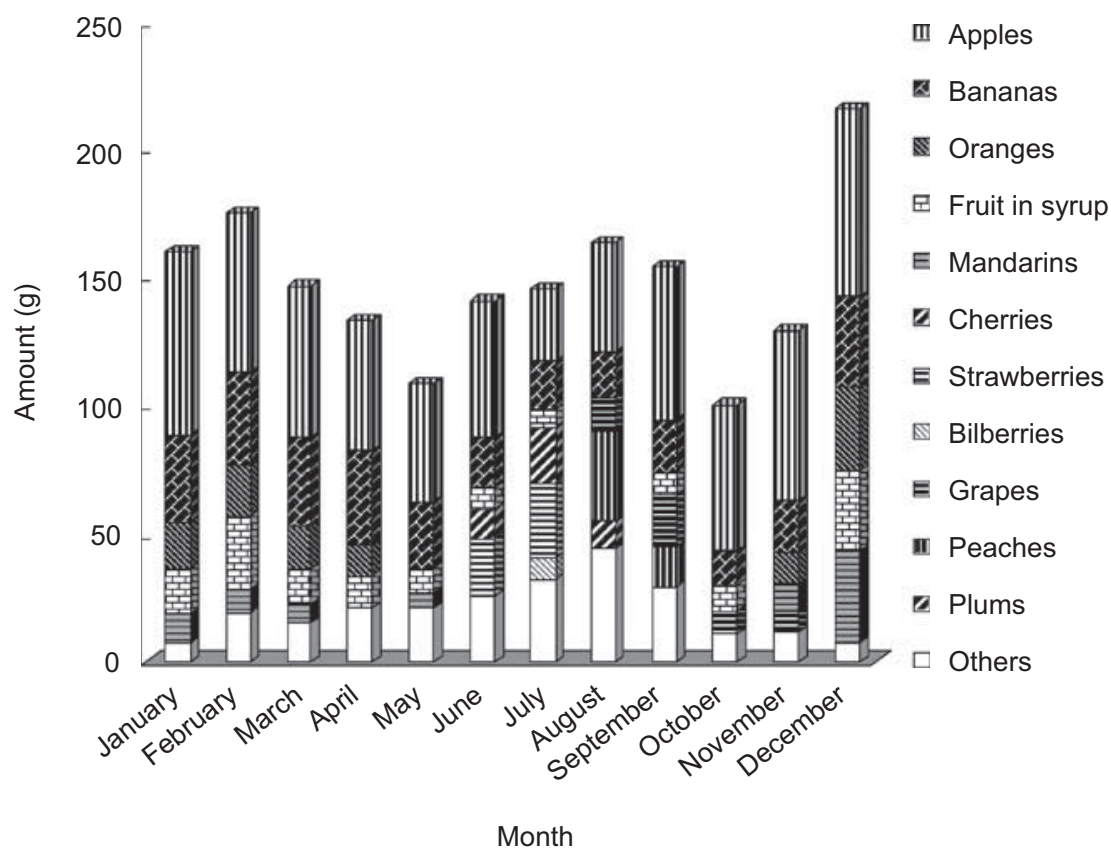

Fig. 2 Proportion of different kinds of fruit in the total intake during the year among Czech children aged 4-14 years

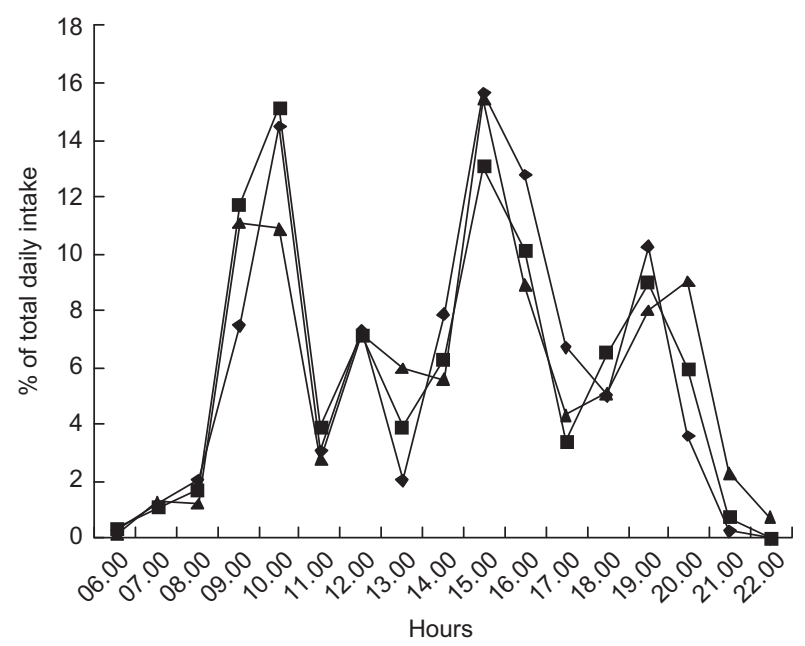

Fig. 3 Daily variations in fruit consumption in the Czech child population aged $4-6$ years $(-\downarrow-), 7-10$ years $(-\mathbf{n}-)$ and 11-14 years $(-\mathbf{\Delta}-)$

Available statistical tools allow estimation of long-term intake based on short-term measurements such as $24 \mathrm{~h}$ recalls. Only two repeated measurements, which cover all seasons and week days, are required for the calculation ${ }^{(28)}$.

The usual intake recognized in the studied sample confirmed the expectation that Czech children consume an insufficient amount of fruit and vegetables. Intakes of these food groups in all age categories fell short of national recommendations ${ }^{(20,21)}$ and the WHO population goal $(400 \mathrm{~g} / \mathrm{d})^{(7)}$. Since the presented recommendations are intended for the general population it is not entirely clear how to apply them to children. Similar studies in which fruit and vegetable consumption in children was investigated compared results directly with the WHO population goal or national food-based dietary guidelines. The American Institute for Cancer Research/World Cancer Research Fund states that fruit and vegetables should make up $7 \%$ or more of the total energy intake ${ }^{(29)}$. If energy requirement values published in the report of the European Scientific Committee for Food ${ }^{(30)}$ are applied, calculated minimum intakes of fruit and vegetables correspond to $251 \mathrm{~g} / \mathrm{d}$ in children aged 4-6 years, $286 \mathrm{~g} / \mathrm{d}$ in children aged 7-10 years, and $311 \mathrm{~g} / \mathrm{d}$ for girls and $369 \mathrm{~g} / \mathrm{d}$ for boys aged 11-14 years. Although these calculated amounts are lower, the fruit and vegetable intakes (without fruit juices and potatoes) in the Czech children failed to achieve even these adjusted recommendations.

The outcomes of our study are similar to results in other countries. Mean fruit and vegetable intake ranging from 143 to $265 \mathrm{~g} / \mathrm{d}$ was observed in a survey focused on 11-year-old children from nine European countries. The highest consumption was recorded in Austria, Portugal, Denmark and Sweden; conversely the lowest consumption was seen in Iceland and, surprisingly, Spain ${ }^{(27)}$. In our group of 11-14year-old Czech children the observed average fruit and vegetable intake was 284 (SD 133) g/d in boys and 261 (SD 140) $\mathrm{g} / \mathrm{d}$ in girls. The data from both studies are comparable because $24 \mathrm{~h}$ recalls combined with the FFQ were used for assessing consumption in the above-mentioned European research. Higher consumption of fruit over vegetables was detected among our Czech children. Such findings were also described in other studies in which fruit and vegetable intakes or eating patterns were investigated $^{(26,27,31,32)}$. A preference of children for foods with a sweeter taste is thought to be the reason for this ${ }^{(32)}$. 


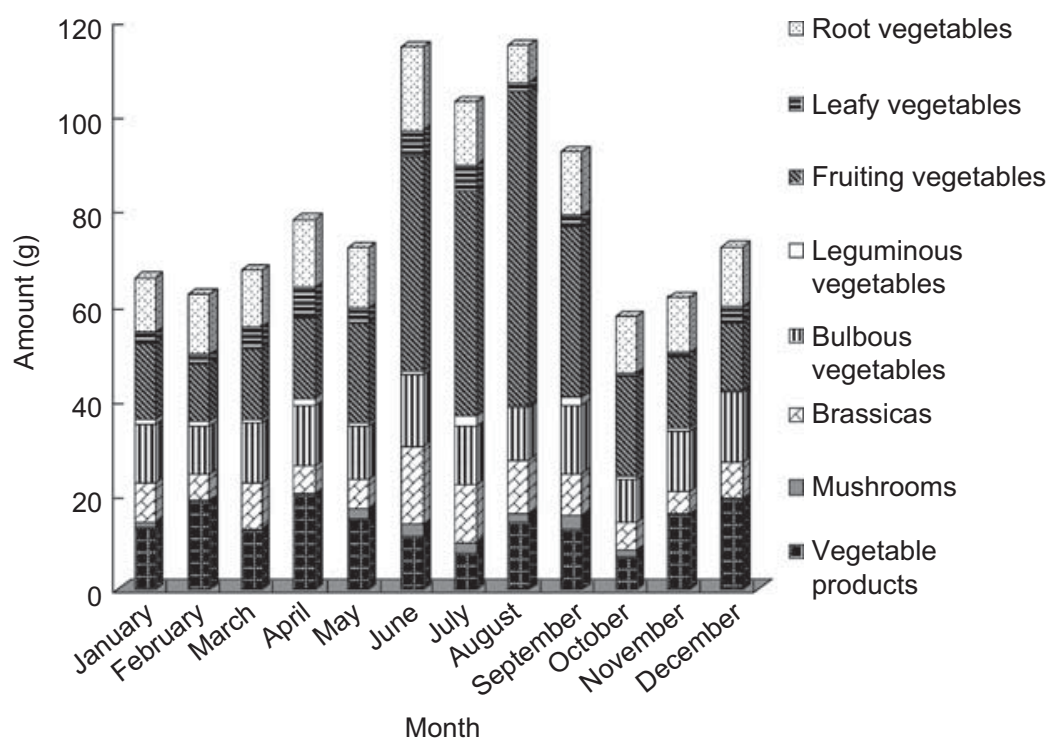

Fig. 4 Proportion of vegetable subgroups in the total intake during the year among Czech children aged 4-14 years

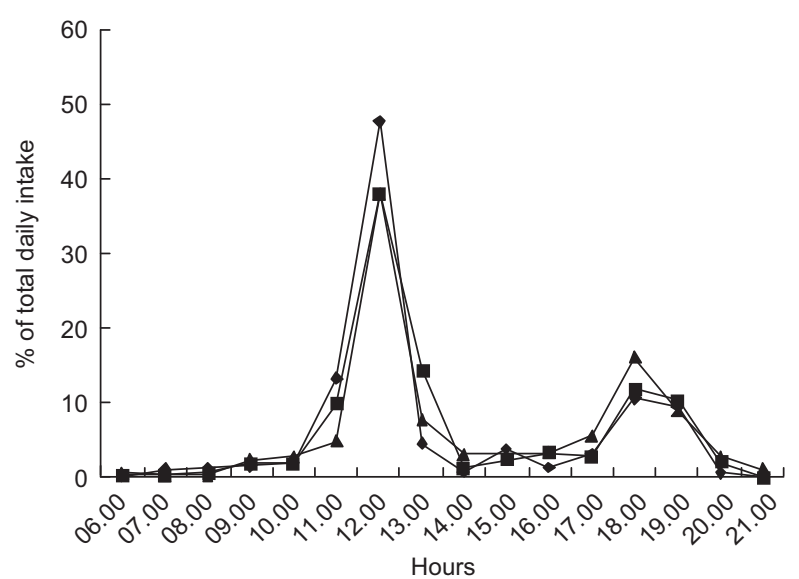

Fig. 5 Daily variations in vegetable consumption in the Czech child population aged $4-6$ years $(-\downarrow), 7-10$ years $(-\mathbf{\square}-)$ and $11-14$ years $(-\mathbf{\Delta}-)$

A fairly low variety of consumed fruit and vegetables was seen in the researched sample (see Figs 2 and 4). Apples were the most frequently eaten fruit type, accounting for $40 \%$ of overall fruit consumption. This result was to be expected because apples are commonly grown in the Czech Republic, are available all year round and are mostly inexpensive. Apple predominance in fruit consumption was also observed in an international survey aimed at adults. Apples were recognized as the most frequently consumed fruit in all countries participating in the European Prospective Investigation into Cancer and Nutrition (EPIC), accounting on average for $25 \%$ of the total fruit intake ${ }^{(33)}$. Only three sorts of fruits - apples, bananas and oranges - presented $70 \%$ of the total fruit intake in the group of Czech children. Similar findings were identified in the northern and western countries studied in EPIC (Germany, Sweden, Denmark and
Norway) ${ }^{(33)}$. Berries and stone fruits, which are also commonly cultivated in the Czech Republic, were consumed less, mostly during the summer. The explanation for this could be the lower availability of these fruits on the market in off-season months. A relatively low diversity of consumed vegetables was also seen. The reason could again be lower supply, but most likely is related to the fact that vegetables are not a dominant part of Czech cuisine. Not many vegetable types are traditionally used for meal preparation and use of non-traditional ones is spreading only tentatively.

Levels of fruit and vegetable intake are often affected by seasonality. The highest vegetable consumption among Czech children was seen in summer months, when fresh vegetables have better availability and are less expensive. Many families also grow their own vegetables during summer, thus supplementing their intake. Seasonal changes in fruit intake distribution were different. The highest level of consumption was recorded in December, when fruit consumption is traditionally considerable during Christmas, mostly consisting of citruses and tropical fruit. Relatively high consumption was detected in January and February. This can be associated with attempted prevention of respiratory diseases which are common at this time among the child population.

Fruit and vegetable consumption was studied in relation to BMI in the Czech children. Statistically significant differences in fruit and vegetable consumption were not detected between groups of children with normal weight and overweight or obese children; nor have any such differences been confirmed by any other studies ${ }^{(32,34,35)}$. On the other hand, a relationship between amounts of fruit and vegetables consumed and BMI was described in Lakkakula et al.'s survey ${ }^{(32)}$ where results suggested that children with low fruit and vegetable intake were at higher risk of obesity than those with higher consumption. 
The availability of fruit and vegetables appears to be an important factor affecting the dietary patterns of children $^{(13,36)}$ and schools have been identified as a favourable setting for intervention. Taking into account the variations in fruit and vegetable consumption during the course of a day among Czech children, the question is whether a programme aimed at fruit distribution in schools would increase total fruit intake or just replace fruit brought by children as a snack from home. Available surveys confirm the usefulness of projects where fruit distribution was connected with multi-component programmes ${ }^{(37)}$. The effects of vegetable distribution in schools are not so clear. Most of the projects have focused on fruit only and those which were also aimed at vegetable intake concluded that interventions for increasing vegetable consumption are less successful ${ }^{(16,37)}$.

\section{Conclusions}

Fruit and especially vegetable consumption is low among Czech children. Ascertained intakes of fruit and vegetables did not reach national recommendations or the WHO population goal in any of the surveyed age categories. Intakes were also lower than corrected recommendations based on minimal energy share of fruit and vegetables in the diet. The amount of fruit consumed exceeded the amount of vegetables consumed in all age groups, which is actually the direct opposite of what is recommended. Variety in consumed types of fruit and vegetables was also low.

The results demonstrate the necessity of altering dietary patterns in the Czech child population and underline the suitability of interventions. Programmes realized at schools appear to be appropriate promotional instruments, but a regular part of them should also be an evaluation of changes in children's nutritional habits.

\section{Acknowledgements}

This research received no specific grant from any funding agency in the public, commercial or not-for-profit sectors. There has been no conflict of interest. M.J. wrote the first draft of the manuscript; M.D. and J.R. discussed and revised the draft and approved the final version.

\section{References}

1. Nikolic M, Nikic D \& Petrovic B (2008) Fruit and vegetable intake and the risk for developing coronary heart disease. Cent Eur J Public Health 16, 17-20.

2. He FJ, Nowson CA, Lucas M et al. (2007) Increased consumption of fruit and vegetables is related to a reduced risk of coronary heart disease: meta-analysis of cohort studies. J Hum Hypertens 21, 717-728.

3. Dauchet L, Amouyel P, Hercberg S et al. (2006) Fruit and vegetable consumption and risk of coronary heart disease: a meta-analysis of cohort studies. J Nutr 136, 2588-2593.
4. He FJ, Nowson CA \& MacGregor GA (2006) Fruit and vegetable consumption and stroke: meta-analysis of cohort studies. Lancet 367, 320-326.

5. Key TJ, Schatzkin A, Willet WC et al. (2004) Diet, nutrition and the prevention of cancer. Public Health Nutr 7, 187-200.

6. World Cancer Research Fund/American Institute for Cancer Research (2007) Food, Nutrition, Physical Activity, and the Prevention of Cancer: A Global Perspective. Washington, DC: WCRF/AICR.

7. World Health Organization (2003) Diet, Nutrition and the Prevention of Chronic Diseases. Joint WHO/FAO Expert Consultation. WHO Technical Report Series no. 916. Geneva: WHO.

8. Sherry B (2005) Food behaviors and other strategies to prevent and treat pediatric overweight. Int J Obes (Lond) 29, 116-126.

9. Rolls BJ, Ello-Martin JA \& Tohill BC (2004) What can intervention studies tell us about the relationship between fruit and vegetable consumption and weight management? Nutr Rev 62, 1-17.

10. World Health Organization (2007) The Challenge of Obesity in the WHO European Region and the Strategies for Response. Copenhagen: WHO Regional Office for Europe.

11. Nicklaus S (2009) Development of food variety in children. Appetite 52, 253-255.

12. Havas S, Heimendinger J, Damron D et al. (1995) 5 a Day for better health - nine community research projects to increase fruit and vegetable consumption. Public Health Rep 110, 68-79.

13. Klepp KI, Perez-Rodrigo C, De Bourdeaudhuij I et al. (2005) Promoting fruit and vegetable consumption among European schoolchildren: rationale, conceptualization and design of the Pro Children Project. Ann Nutr Metab 46, 212-220.

14. European Commission Directorate-General for Agriculture and Rural Development (2009) DG AGRI working document for managing the EU School fruit scheme. http:// ec.europa.eu/agriculture/markets/fruitveg/sfs/documents/ guidelines_en.pdf (accessed December 2009).

15. Reinaerts E, Crutzen R, Candel $M$ et al. (2008) Increasing fruit and vegetable intake among children: comparing long-term effects of a free distribution and a multicomponent program. Health Educ Res 23, 987-996.

16. Bere E, Veierød MB \& Klepp K-I (2005) The Norwegian School Fruit Programme: evaluating paid vs. no-cost subscription. Prev Med 41, 463-470.

17. de Sa J \& Lock K (2008) Will European agricultural policy for school fruit and vegetables improve public health? A review of school fruit and vegetable programmes. Eur J Public Health 18, 558-568.

18. Knai J, Pomerleau J, Lock K et al. (2006) Getting children to eat more fruit and vegetables: a systematic review. Prev Med 42, 85-95.

19. French SA \& Stables G (2003) Environmental interventions to promote vegetable and fruit consumption among youth in school settings. Prev Med 27, 593-610.

20. Dostalova J, Kunesova M, Otoupal P et al. (2006) Zdravá třináctka - stručná výživová doporučení (Healthy 13 - a brief dietary guidelines). Vyživa a potraviny 1, 7 .

21. Ministry of Health (2005) Výživová doporučení pro obyvatelstvo $\check{C} R$ (Dietary Guidelines for the Czech Population), 1st ed. Prague: Ministry of Health.

22. Ruprich J, Dofkova M, Rehurkova I et al. (2006) Individual food consumption - the national study SISP04. http://www. chpr.szu.cz/spotrebapotravin.htm (accessed December 2009).

23. Vignerova J (2001) The 6th Nationwide Anthropological Survey of Children and Adolescents 2001. Prague: National Institute of Public Health; available at http://www.szu.cz/ publikace/data/6-celostatni-antropologicky-vyzkum

24. Vignerova J, Humenikova L, Paulova M et al. (2008) Prevalence of overweight, obesity and low weight in the Czech child population up to 18 years of age in the last 50 years. $J$ Public Health 16, 413-420. 
25. Agudo A (2004) Measuring intake of fruit and vegetables. Background paper presented at the Joint FAO/WHO Workshop on Fruit and Vegetables for Health, Kobe, Japan, 1-3 September 2004.

26. Gibson EL, Wardle J \& Watts CJ (1998) Fruit and vegetable consumption, nutritional knowledge and beliefs in mothers and children. Appetite 31, 205-228.

27. Yngve A, Wolf A, Poortvliet E et al. (2005) Fruit and vegetable intake in a sample of 11 -year-old children in 9 European countries: the Pro Children cross-sectional survey. Ann Nutr Metab 49, 236-245.

28. Hoffmann K, Boeing H, Dufour A et al. (2002) Estimating the distribution of usual dietary intake by short-term measurements. Eur J Clin Nutr 56, Suppl. 2, S53-S62.

29. Glade MJ (1999) Food, Nutrition, and the Prevention of Cancer: A Global Perspective. Nutrition 15, 523-526.

30. Commission of the European Communities (1993) Nutrient and Energy Intakes for the European Community. Reports of the Scientific Committee for Food (Thirty-first series). Luxembourg: Office for Official Publications of the European Communities.

31. Basch C, Zybert P \& Shea S (1994) 5-A-DAY: dietary behavior and the fruit and vegetable intake of Latino children. Am J Public Health 84, 814-818.
32. Lakkakula AP, Zanovec M, Silverman L et al. (2008) Black children with high preferences for fruits and vegetables are at less risk of being at risk of overweight or overweight. J Am Diet Assoc 108, 1912-1915.

33. Agudo A, Slimani N, Ocke M et al. (2002) Consumption of vegetables, fruit and other plant foods in the European Prospective Investigation into Cancer and Nutrition (EPIC) cohorts from 10 European countries. Public Health Nutr $\mathbf{5}$, 1179-1196.

34. Patterson B, Block G, Rosenberger W et al. (1990) Fruit and vegetables in the American diet: data from the NHANES II survey. Am J Public Health 80, 1443-1449.

35. Van Sluijs E, Skidmore P \& Mwanza K (2008) Physical activity and dietary behaviour in a population-based sample of British 10-year old children: the SPEEDY study (Sport, Physical activity and Eating behaviour: Environmental Determinants in Young people). BMC Public Health 14, 388.

36. Neumark-Sztainer D, Wall M, Perry C et al. (2003) Correlates of fruit and vegetable intake among adolescents: findings from Project EAT. Prev Med 37, 198-208.

37. Ciliska D, Miles E, O'Brien MA et al. (2000) Effectiveness of community-based interventions to increase fruit and vegetable consumption. J Nutr Educ Behav 32, 341-352. 